\title{
Solution of Supplier Selection Problem with Random Demand Using Probabilistic Multistage Programming Approach
}

\author{
Fauzan Al'ansory ${ }^{1}$, Sutrisno ${ }^{2}$, Bambang Irawanto ${ }^{3}$ \\ ${ }^{1,2,3}$ (Department of Mathematics, Diponegoro University, Semarang, Indonesia)
}

\begin{abstract}
Supplier selection is a problem of determining the optimal supplier $(s)$ which are capable to supply a product (raw material) in order to meet the demand so that the total procurement cost is minimal. When the supplier selection problem involving some uncertain parameter, an appropriate optimization method will be necessary. In this paper, we formulate a mathematical model in a probabilistic integer quadratic optimization to solve a multi-product and multi-period supplier selection problem with uncertain demand. The demand is considered as a random variable with some probability distribution. The constraints of the model are covering supplier capacity, inventory management, quality level management and budgetary constraint. To determine the optimal decision, we use scenario based probabilistic multistage programming. Based on the numerical experiment that we discussed, it can be conclude that the proposed model generated the optimal decision which is the optimal product volume for each product that should be purchased from each supplier which gave the minimum total procurement cost.
\end{abstract}

Keywords: Supplier selection, probabilistic integer quadratic programming, probabilistic demand

\section{Introduction}

Along with increasingly competition in business and to meet the growing of customer's demand, a business enterprise is required to optimize all aspects of business operations that are concerned with maintaining desired quality standards on product and process. One to be noted is every company must maintain a good relationship with suppliers because the role of suppliers is very important in meeting all needs of the company. In supplier selection, there are several aspects that must be considered in the decision-making process which are making or buying, contract negotiations, design collaboration, procurement, and analysis of sources. However, from some aspects of the decision, supplier selection is the important one because it is responsible for keeping the company competitive. In the process of supplier selection, it is required a good planning in determining of the right supplier for all periods so that the expected total cost incurred is minimum.

Model approaches in supplier selection problem solving can be categorized into two categories which are quantitative model and qualitative model. In the quantitative model category, S.H. Ghodsypour and C. O'Brien have addressed the supplier selection issue that explains the integration of the hierarchy analysis process with linear programming to select the best supplier and the optimum order quantity so that the total purchase cost is minimum where the cost component is only purchase cost [1]. The article was developed by C. X. Feng, J. Wang, and J.S. Wang considering purchase cost component is influenced by product quality with its solution method using stochastic integer programming [2]. An article re-developed by S.H. Ghodsypour and C. O'Brien was added the transportation cost and storage cost components with the method of solution is using economic order quantity concept to minimize total cost [3]. The next supplier selection issues are then discussed by $\mathrm{H}$. Ding, L. Benyoucef and Xiaolan Xie with ONE (optimization methodologies for Network Enterprises) method [4]. Furthermore, the problem was developed by Nilesh R. Ware, S. P Singh, and D.K Banwet with cost component is purchase cost, transportation cost, penalty cost, and delay cost in deterministic case and its solve by mixed integer non-linear programming approach [5]. In the qualitative model category, supplier selection problem has been discussed with Analytical Network Process (ANP) approach in [6, 7], seller profile analysis in [8], supplier selection with seller performance matrix approach in [9], suppliers selection by using the Analitycal Hierarchy Process (AHP) approach in $[10,11]$ and Technique for Others Reference by Similarity to Ideal Solution (TOPSIS) and Fuzzy TOPSIS in [12]. In this paper, we formulate a mathematical model in a probabilistic integer quadratic optimization to solve the supplier selection problem with uncertain demand which considered as a random variable with some known probability distribution where the constraints of the model are covering supplier capacity, inventory management, quality level management and budgetary constraint. A numerical experiment will be given to evaluate the model. 


\section{Mathematical Model}

To formulate the mathematical model, symbols of variables and parameters are introduced as follows:

$T \quad:$ Set of time period;

$S \quad$ : Set of supplier;

$P \quad:$ : Set of product type;

$i \quad$ : Index of scenarios;

$X_{t s p i} \quad:$ Volume of product $p \in P$ supplied $\mathrm{s} \in S$ for time period $t \in T$ for scenarios $i$

$U C_{t s p} \quad:$ Unit cost of product $p \in P$ for supplier $s \in S$ for time period $t \in T$;

$T C_{t s} \quad:$ Total transportation cost for product (irrespective of product type) by supplier $s \in S$ for time period $t \in T$;

$Y_{t s} \quad:$ Supplier assignment $s \in S$ for time period $t \in T$ (1 for $X_{t s p i}>0,0$ for others);

$S C_{t s p} \quad:$ Capacity of supplier $s \in S$ for product $p \in P$ for time period $t \in T$;

$D_{t p i} \quad:$ Random variable of volume product $p \in P$ for time period $t \in T$ for scenarios $i$;

$U P C_{t s p}$ : Unit penalty cost to supplier $s \in S$ for product $p \in P$ for time period $t \in T$;

$U D C_{t s p}$ : Unit delay cost to supplier $s \in S$ for product $p \in P$ for time period $t \in T$;

$D L T_{t s p}$ : Delay lead time of supplier $s \in S$ for product $p \in P$ for time period $t \in T$;

$Q_{t s p} \quad:$ Quality level in period $t \in T$ of supplier $s \in S$ products $p \in P$;

$V_{t p} \quad:$ Volume of product inventory $p \in P$ for time period $t \in T$;

$M_{p} \quad:$ Inventory capacity $p \in P$

$B_{t} \quad$ : Company's budget at time period $t \in T$;

$C h_{p} \quad$ : Holding cost of product $p \in P$

$V_{0} \quad$ : Volume of inventory at the beginning of the period;

$Q_{0} \quad$ : Quality level set by organization.

Expected total cost for entire period $(Z)$ equals to the probability of the occurred scenario multiplied by total procurement cost which consisting of purchasing cost, fixed transportation cost, delay cost due to late on delivery, penalty cost due to poor product and holding cost. Let be the number the scenarios in scenario tree generated by the event space of the random variable demand, the proposed mathematical model which minimize the expected total cost is formulated as follows:

$\min Z=\sum_{i=1}^{\Omega} \operatorname{pro}_{i}\left[\sum_{t=1}^{T} \sum_{s=1}^{S} \sum_{p=1}^{P} X_{t s p i} U C_{t s p}+\sum_{t=1}^{T} \sum_{s=1}^{S} T C_{t s} Y_{t s}+\sum_{t=1}^{T} \sum_{s=1}^{S} \sum_{p=1}^{P}(1\right.$

$$
\left.\left.-Q_{t s p}\right) U P C_{t s p} X_{t s p i} Y_{t s}+\sum_{t=1}^{T} \sum_{s=1}^{S} \sum_{p=1}^{P} U D C_{t s p} D L T_{t s p} X_{t s p i} Y_{t s}+\sum_{t=1}^{T} \sum_{p=1}^{P} C h_{p} V_{t p}\right]
$$

subject to:

$$
X_{t s p i} \leq S C_{t s p}, \forall t \in T, \quad \forall s \in S, \forall p \in P, \forall i \in \Omega
$$

$$
\begin{aligned}
& \left(\sum_{s t=1}^{T} D_{t p i}\right) Y_{t s} \geq X_{t s p i}, \quad \forall t \in T, \forall p \in P, \forall i \in \Omega \\
& Q_{t s p} \geq Q_{0} \quad \forall t \in T, \quad \forall s \in S, \forall p \in P \\
& Y_{t s}=\left\{\begin{array}{ll}
1 & \text { for } \quad X_{t s p i}>0 \\
0
\end{array}, \forall t \in T, \forall s \in S\right. \\
& X_{t s p i} \geq 0 \quad \forall t \in T, \quad \forall s \in S, \quad \forall p \in P, \quad \forall i \in \Omega \\
& \sum_{s=1}^{s} X_{t s p i}-V_{t p} \geq D_{t p i}, t=1, \forall p \in P, \quad \forall i \in \Omega
\end{aligned}
$$




$$
\begin{aligned}
& V_{t-1, p}+\sum_{s=1}^{s} X_{t s p i}-V_{t p} \geq D_{t p}, t>1, \forall p \in P, \forall i \in \Omega \\
& V_{t p} \leq M_{p}, \forall t \in T, \forall p \in P \\
& \sum_{s=1}^{S} \sum_{p=1}^{P} X_{t s p i} U C_{t s p}+\sum_{s=1}^{S} T C_{t s} Y_{t s}+\sum_{s=1}^{S} \sum_{p=1}^{P}\left(1-Q_{t s p}\right) U P C_{t s p} X_{t s p i} Y_{t s}+\sum_{s=1}^{S} \sum_{p=1}^{P} U D C_{t s p} D L T_{t s p} X_{t s p i} Y_{t s} \\
& +\sum_{p=1}^{P} C h_{p} V_{t p} \leq B_{t}, \forall t \in T, \forall i \in \Omega \\
& X_{t s p i} \text { integer, } \forall t \in T, \forall s \in S, \forall p \in P, \forall i \in \Omega \\
& V_{t p} \text { integer, } \forall t \in T, \forall p \in P .
\end{aligned}
$$

The cost components in the objective function are respectively represent the purchasing cost, transportation cost, penalty cost for poor product, penalty cost for belated product and holding cost. The constraints in the model are respectively explains the demand satisfying, quality level management, supplier assignment, inventory management, budgetary constraint and integer constraint.

\begin{tabular}{|c|c|c|}
\hline Unit Demand $\left(D_{t p i}\right)$ & Probability $\left(\Omega_{i}\right)$ & Parameter \\
\hline 160 & 0.4 & \multirow{2}{*}{$D_{11}, D_{21}, D_{31}$} \\
\hline 200 & 0.6 & \\
\hline 240 & 0.6 & \multirow{2}{*}{$D_{12}, D_{22}, D_{32}$} \\
\hline 320 & 0.4 & \\
\hline 180 & 0.5 & \multirow{2}{*}{$D_{13}, D_{23}, D_{33}$} \\
\hline 250 & 0.5 & \\
\hline 200 & 0.4 & \multirow{2}{*}{$D_{41}, D_{51}, D_{61}$} \\
\hline 250 & 0.6 & \\
\hline 180 & 0.6 & \multirow{2}{*}{$D_{42}, D_{52}, D_{62}$} \\
\hline 220 & 0.4 & \\
\hline 240 & 0.5 & \multirow{2}{*}{$D_{43}, D_{53}, D_{63}$} \\
\hline 300 & 0.5 & \\
\hline 200 & 0.4 & \multirow{2}{*}{$D_{71}, D_{81}, D_{91}$} \\
\hline 240 & 0.6 & \\
\hline 250 & 0.6 & \multirow{2}{*}{$D_{72}, D_{82}, D_{92}$} \\
\hline 300 & 0.4 & \\
\hline 180 & 0.5 & \multirow{2}{*}{$D_{73}, D_{83}, D_{93}$} \\
\hline 280 & 0.5 & \\
\hline
\end{tabular}

\section{Numerical Experiment}

Supposed a supplier selection problem with three products $p_{1}, p_{2}$, and $p_{3}$ and two suppliers $s_{1}$ and $s_{2}$. The demand of each product at some time period is uncertain where its probability distribution is known given in Table 1 and the value of parameters used in this numerical experiment are given in Appendix 1.

Table 1. Probability distribution of demand

If the quality level is 0.85 , then how many products should be purchased at each time period for nine time periods from each supplier with minimum expected total cost can be determined by using model (1). We solve the corresponding probabilistic integer quadratic programming in LINGO. To solve the problem for nine time periods, we solve (1) with 3-by-3 time periods due to the computer's memory capacity limit. For each 3 time periods, the number of scenario generated in LINGO is 8 scenarios so the corresponding optimization is a sufficiently large problem. To illustrate the solution of the problem, we decide the demand value from a scenario so that the corresponding optimal solution can be determined as follows. 


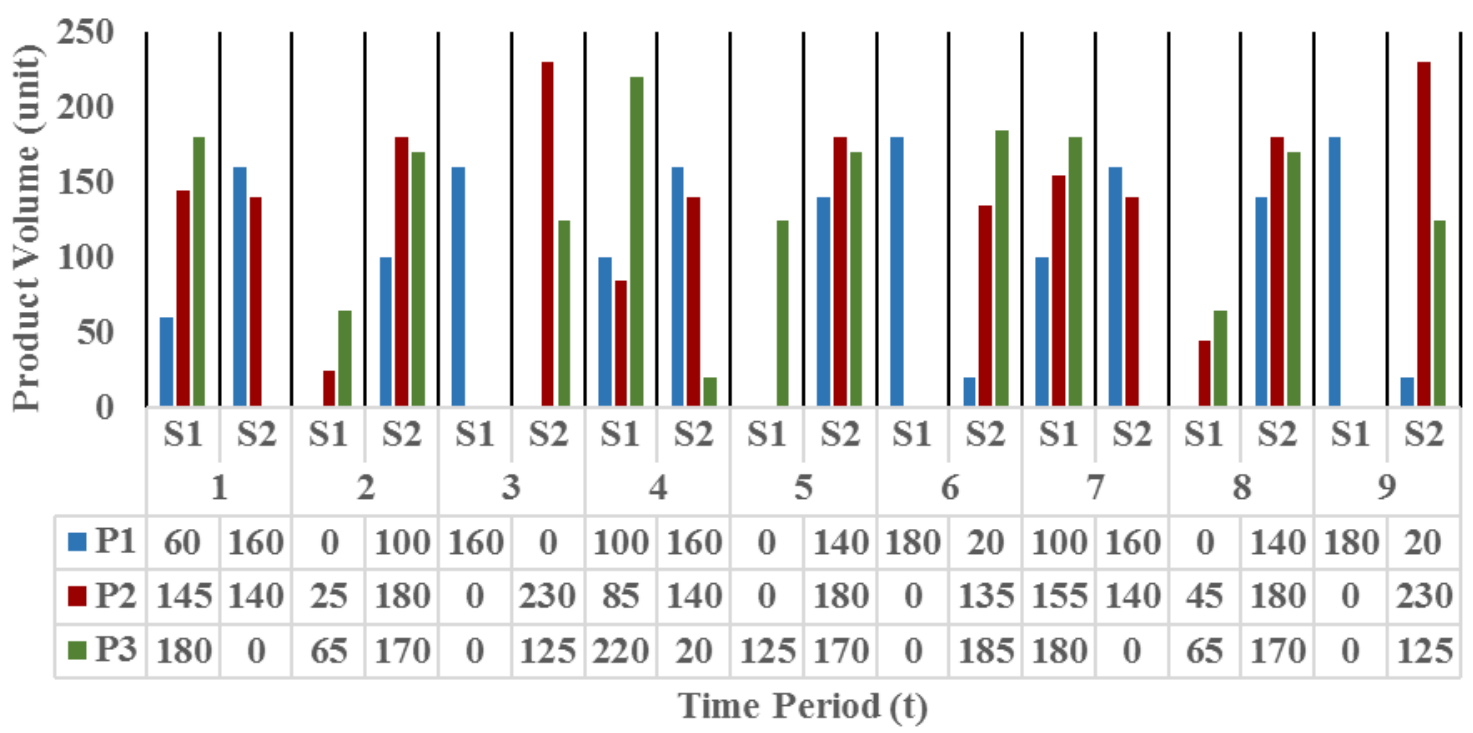

Figure 1. Optimal product volume generated by optimization (1) (P1, P2, P3 refers to $p_{1}, p_{2}, p_{3}$ and S1, S2 refers to $s_{1}, s_{2}$ )

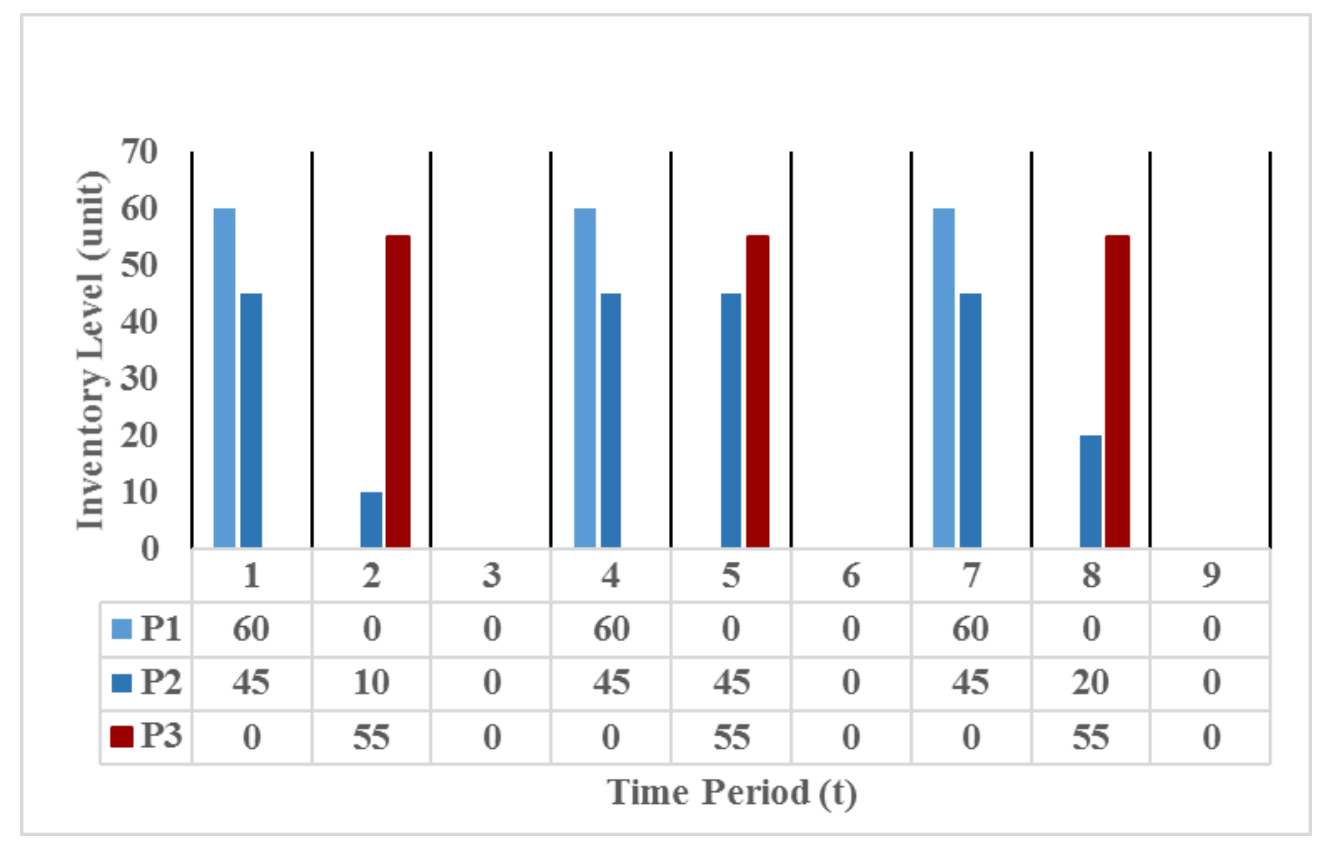

Figure 2. Inventory level of product generated by optimization (1)

At time period 1, if demand for $p_{1}$ is 160 units, $p_{2}$ is 240 units, $p_{3}$ is 180 units then the company have to purchase 60 units of $p_{1}$ from $s_{1}, 160$ units from $s_{2}$ while the inventory level is 60 units; purchase 145 units of $p_{2}$ from $s_{1}, 140$ units from $s_{2}$ while the inventory level is 45 units and purchase 180 units of $p_{3}$ from $s_{1}$ while no item in the inventory. At time period 2, if demand for $p_{1}$ is 200 units, $p_{2}$ is 320 units, $p_{3}$ is 250 units then the company have to purchase 140 units of $p_{1}$ from $s_{2}$ with no item in the inventory; purchase 105 units of $p_{2}$ from $s_{1}, 180$ units from $s_{2}$ while the inventory level is 10 units; purchase 135 units of $p_{3}$ from $s_{1}$, 170 units from $s_{2}$ while the inventory level is 55 units. By solving the problem analogously for time period 3 to 9, the minimal expected total cost is $\$ 376485.9$ where the solution is illustrated by Fig. 1 and Fig. 2. 


\section{Conclusion}

In this paper, the solution of supplier selection problem with uncertain demand was considered where the demand's uncertainty was approached by using a probability distribution. The optimal decision which is the product volume that has to be purchased from each supplier with minimal expected total cost was determined by using the proposed mathematical model where the corresponding optimization problem was solved by using probabilistic integer quadratic programming. From the numerical experiment result, the proposed model was generated the optimal decision for the given problem.

\section{References}

[1]. S. H. Ghodsypour C. O'Brien, "A decision support system for supplier selection using an integrated analytic hierarchy process and linear programming," International Journal of Production Economics, Vols. 56-57, pp. 199-212, 1998.

[2]. C.X. Feng, J. Wang, \& J.S. Wang, "An optimization model for concurrent selection of tolerances and suppliers," Computers \& Industrial Engineering, vol. 40, pp. 15-33, 2001.

[3]. S.H. Ghodsypour \& C. O'Brien, "The total cost of logistics in supplier selection, under conditions of multiple sourcing, multiple criteria and capacity constraint," International Journal of Production Economics , vol. 73, pp. 15-27, 2001.

[4]. H. Ding, L. Benyoucef, \& X. Xie, "A simulation optimization methodology for supplier selection problem," International Journal of Computer Integrated Manufacturing, vol. 18, no. 2-3, pp. 210-224, 2005.

[5]. Nilesh R. Ware, S.P. Singh, \& D.K. Banwet, "A mixed-integer non-linear program to model dynamic supplier selection problem," Expert Systems with Applications, vol. 41, pp. 671-678, 2014.

[6]. Wei, Chia; H, Allen H;, "Applying hazardous substance management to supplier selection using analytic network process," Journal of Cleaner Production, vol. 17, pp. 255-264, 2009.

[7]. B. O, "Use of analytic network process in vendor selection decisions," Benchmarking: An International Journal, vol. 13, pp. 566$579,2006$.

[8]. T. K. N, "Vendor profile analysis," Journal of Purchasing and Materials Management, pp. 11-18, 1990.

[9]. S. W. R, "Supplier selection strategies," Journal of Purchasing and Materials Management, vol. 77, 1987.

[10]. S. T. L, "How to make decision: The analytical decision process," European Journal of Operation Research, vol. 48, pp. 9-26, 1990.

[11]. L, Nydik R; P, Hill R;, "Using the analytic hierarchy process to structure the supplier selection procedure," International Journal of Purchasing and Materials Management, vol. 28, pp. 31-36, 1992.

[12]. E, Boran F; S, Genc; M, Kurt; A, Diyar;, "A Multi-criteria intuitionistic fuzzy group decision making for supplier selection with TOPSIS method," Expert Systems with Applications, vol. 36, pp. 11363-11368, 2009.

Appendix 1. Value of parameters

\begin{tabular}{|c|c|c|c|c|c|}
\hline $\begin{array}{c}\text { Time } \\
\text { period } \\
(t)\end{array}$ & $s$ & $p_{1}$ & $p_{2}$ & $p_{3}$ & $T C_{t s}$ \\
\hline \multirow{2}{*}{1} & $s_{1}$ & $200,45,0.95,6,3,15^{*}$ & $240,23,0.92,7,2,18$ & $220,29,0.91,6.5,0,16$ & 9 \\
\hline & $s_{2}$ & $160,55,0.89,6,2,15$ & $140,21,0.96,7,0,18$ & $150,32,092,6.5,2,16$ & 11.5 \\
\hline \multirow{2}{*}{2} & $s_{1}$ & $220,60,0.86,7,3,19$ & $200,38,0.88,10,2,16$ & $210,45,0.87,8,1,17$ & 15 \\
\hline & $s_{2}$ & $160,65,0.87,7,2,19$ & $180,36,0.91,10,0,16$ & $170,40,0.9,8,1,17$ & 18 \\
\hline \multirow{2}{*}{3} & $s_{1}$ & $180,30,0.94,8,1,17$ & $160,47,0.93,9,2,17.5$ & $170,38,0.89,7,2,18$ & 13.5 \\
\hline & $s_{2}$ & $210,33,0.88,8,2,17$ & $230,41,0.91,9,1,17.5$ & $220,36,0.9,7,2,18$ & 14 \\
\hline \multirow{2}{*}{4} & $s_{1}$ & $200,45,0.95,6,3,15$ & $240,23,0.92,7,2,18$ & $220,29,0.91,6.5,0,16$ & 9 \\
\hline & $s_{2}$ & $160,55,0.89,6,2,15$ & $140,21,0.96,7,0,18$ & $150,32,0.92,6.5,2,16$ & 11.5 \\
\hline \multirow{2}{*}{5} & $s_{1}$ & $220,60,0.86,7,3,19$ & $200,38,0.88,10,2,16$ & $210,45,0.87,8,1,17$ & 15 \\
\hline & $s_{2}$ & $160,65,0.87,7,2,19$ & $180,36,0.91,10,0,16$ & $170,40,0.9,8,1,17$ & 18 \\
\hline \multirow{2}{*}{6} & $s_{1}$ & $180,30,0.94,8,1,17$ & $160,47,0.93,9,2,17.5$ & $170,38,0.89,7,2,18$ & 13.5 \\
\hline & $s_{2}$ & $210,33,0.88,8,2,17$ & $230,41,0.91,9,1,17.5$ & $220,36,0.9,7,2,18$ & 14 \\
\hline \multirow{2}{*}{7} & $s_{1}$ & $200,45,0.95,6,3,15$ & $240,23,0.92,7,2,18$ & $220,29,0.91,6.5,0,16$ & 9 \\
\hline & $s_{2}$ & $160,55,0.89,6,2,15$ & $140,21,0.96,7,0,18$ & $150,32,0.92,6.5,2,16$ & 11.5 \\
\hline \multirow{2}{*}{8} & $s_{1}$ & $220,60,0.86,7,3,19$ & $200,38,0.88,10,2,16$ & $210,45,0.87,8,1,17$ & 15 \\
\hline & $s_{2}$ & $160,65,0.87,7,2,19$ & $180,36,0.91,10,0,16$ & $170,40,0.9,8,1,17$ & 18 \\
\hline \multirow{2}{*}{9} & $s_{1}$ & $180,30,0.94,8,1,17$ & $160,47,0.93,9,2,17.5$ & $170,38,0.89,7,2,18$ & 13.5 \\
\hline & $s_{2}$ & $210,33,0.88,8,2,17$ & $230,41,0.91,9,1,17.5$ & $220,36,0.9,7,2,18$ & 14 \\
\hline
\end{tabular}

${ }^{*}\left\{S C_{t s p}, U C_{t s p}, Q_{t s p}, U P C_{t s p}, D L T_{t s p}, U D C_{t s p}\right\}, \forall t \in T, \forall s \in S, \forall p \in P$. 